\title{
Spotlight on Asteroid Hyalosis: A Clinical Perspective
}

\author{
Daniel Andrew Richard Scott (iD) \\ Thomas Berner \\ Møller-Lorentzen ${ }^{2}$ \\ Carsten Faber (iD ${ }^{2}$ \\ Jimmi Wied (iD ${ }^{3,4}$ \\ Jakob Grauslund (iD) ${ }^{3-5}$ \\ Yousif Subhi (iD ${ }^{2}$ \\ 'Department of Ophthalmology, Waikato \\ District Health Board, Hamilton, New \\ Zealand; ${ }^{2}$ Department of Ophthalmology, \\ Rigshospitalet, Copenhagen, Denmark; \\ ${ }^{3}$ Department of Ophthalmology, Odense \\ University Hospital, Odense, Denmark; \\ ${ }^{4}$ Department of Clinical Research, \\ University of Southern Denmark, \\ Odense, Denmark; ${ }^{5}$ Steno Diabetes \\ Center Odense, Odense University \\ Hospital, Odense, Denmark
}

\begin{abstract}
Asteroid hyalosis is a benign degenerative condition of the vitreous that is often asymptomatic. Our purpose with this narrative review is to provide a current overview of asteroid hyalosis from a clinical perspective. We review the epidemiology and risk factors, the clinical diagnosis and differential diagnoses, clinical challenges in eyes with asteroid hyalosis, and the treatment of asteroid hyalosis. Many clinical questions remain unanswered, and the current evidence to guide clinical practice is largely based on anecdotal evidence and clinical experience. More studies on asteroid hyalosis from a clinical perspective are warranted.
\end{abstract}

Keywords: asteroid hyalosis, vitreous opacities, Benson's disease, narrative review

\section{Introduction}

Asteroid hyalosis is a benign degenerative condition of the vitreous. It has a clinical appearance of stars (or asteroids) shining in the night sky. Although some individuals experience visual discomfort or blurring, especially if the opacities are densely crowded close to the macula, asteroid hyalosis is generally asymptomatic in the large majority of patients. Hence, asteroid hyalosis is more often a challenge for the eye of the beholder than to the eye with the asteroid hyalosis.

The condition was coined and first described by the Irish ophthalmologist Alfred Hugh Benson (1852-1912) in 1894 as a distinct case different from synchysis scintillans, ${ }^{1}$ and in acknowledgement of Benson's contribution, the condition is also called Benson's disease. In contrast to synchysis scintillans, asteroid hyalosis is sensitive to eye movements (i.e. opacities move with movements) and avoids gravitating downwards. The condition was initially called asteroid hyalitis, ${ }^{1}$ which was later re-phrased to asteroid hyalosis in the 1970s due to absence of an inflammatory process. ${ }^{2}$ The name asteroid hyalosis has roots in Ancient Greek (asteroeidếs, starlike; and hyalinos, glass-like) and it is the most common term for this condition today.

Although the exact pathogenesis of asteroid hyalosis remains unclear, several studies have described these particles in molecular and structural detail. Electron mapping studies have confirmed a homogeneous distribution of elemental calcium, phosphorus, and oxygen distributed within asteroid bodies, with a structure similar to hydroxyapatite. ${ }^{3-7}$ The scanning electron structure appears in a ball-shape, with a pumice stone-like structure, covered with clotted vitreous matrix. ${ }^{3-7}$ These structural characteristics support the theory that the production of asteroid bodies is a degenerative process resembling stones (lithiasis) and therefore it has been
Correspondence: Yousif Subhi Department of Ophthalmology, Rigshospitalet, Valdemar Hansens Vej 3, Glostrup, DK-2600, Denmark

Tel +4538634700

Fax +4538634669

Email ysubhi@gmail.com 
speculated whether asteroid hyalosis could be considered an ocular lithiasis with a genesis similar to that of cholelithiasis and nephrolithiasis. ${ }^{3}$

Our purpose with this narrative review, 127 years after the first description of asteroid hyalosis by Benson, is to provide a current overview of asteroid hyalosis from a clinical perspective. This paper turns the spotlight on asteroid hyalosis, its epidemiology and risk factors, the clinical diagnosis and differential diagnoses, clinical challenges in eyes with asteroid hyalosis, and the treatment of asteroid hyalosis.

\section{Epidemiology and Risk Factors}

The prevalence of asteroid hyalosis has been investigated in several population-based studies. ${ }^{8-10}$ In the Beaver Dam Eye Study of inhabitants in Beaver Dam, Wisconsin, USA, 4747 participants had eligible fundus photographs for evaluation of vitreous opacities. ${ }^{8}$ Here, 57 participants (1.2\%) had vitreous opacities deemed as asteroid hyalosis. ${ }^{8}$ In another large population-based study, the Blue Mountains Eye Study of inhabitants in Blue Mountains, New South Wales, Australia, 3583 participants underwent slit-lamp examination and had stereo fundus photographs from where asteroid hyalosis was diagnosed in 36 participants $(1.0 \%) .{ }^{9}$ The Gutenberg Health Study was a large population-based study in the Rhine-Main region, Germany, where fundus photographs were taken of 12,779 baseline participants. ${ }^{10}$ Here, 61 individuals $(0.5 \%)$ had asteroid hyalosis. ${ }^{10}$ Across these prevalence studies, there is a significant trend of prevalence increase with age ${ }^{8-11}$ In a meta-analysis of the prevalence of asteroid hyalosis, we identified that this ranges from $0.3 \%$ in individuals aged $0-39$ years, to $3.1 \%$ for individuals aged 80 years or above. ${ }^{11}$

Increasing age is to our knowledge the most consistently reported risk factor for asteroid hyalosis. ${ }^{11}$ Another demographic significant risk factor is male gender at an odds ratio of 1.8. ${ }^{11}$ Forecasting analyses indicate that the current global prevalence of asteroid hyalosis is $\sim 42$ million and is expected to increase to 91 million in year $2100 .^{11}$

A number of systemic risk factors have been reported in a range of studies with conflicting findings. Bergren et al. retrospectively evaluated presence of asteroid hyalosis and its association to systemic comorbidities among all patients visiting the primary eye care clinic of Wills Eye Hospital during an eight-month period. ${ }^{12}$ Among 12,205 patients in the study, the authors reported univariable associations between asteroid hyalosis and diabetes mellitus, arterial hypertension, and atherosclerosis. ${ }^{12}$ In a retrospective review of the University of California at Los Angeles autopsy eye database, Fawzi et al. investigated asteroid hyalosis in 10,801 autopsied patients and found no association in multivariable analyses between asteroid hyalosis and systemic comorbidities. ${ }^{13}$ Similar conflicting results on the contribution of systemic risk factors are reported elsewhere, and studies with multivariable analyses seem less likely to report a statistically significant association. ${ }^{8-10,12-15}$ The possible contribution of systemic risk factors to the pathogenesis of asteroid hyalosis remains incompletely understood, and its pathological contribution remains controversial due to the strong unilateral preponderance $(>90 \%)$ of its clinical manifestation. ${ }^{8,9}$

Ocular risk factors investigated include intraocular pressure, refractive error, and the presence of ocular comorbidities. ${ }^{8-10,12-16}$ Studies have so far reported conflicting results with no consistent association of any ocular risk factors to asteroid hyalosis. However, one interesting study by Ikeda et al. reported that the prevalence of asteroid hyalosis in patients with retinitis pigmentosa was $3.1 \%$ (95\% CI $1.5-5.7 \%$ ), which is higher than the prevalence reported in the general population. ${ }^{16}$ The authors vitrectomized eyes with asteroid hyalosis and compared its molecular components to that in controls (vitrectomy due to epiretinal membrane and macular hole) and found that eyes with asteroid hyalosis had a statistically significantly higher level of phosphorus in the vitreous. ${ }^{16}$ Based on these findings, one theory put forward by the authors is that intraocular cellular degeneration, and in the case of retinitis pigmentosa the degeneration of rod photoreceptors, lead to cellular remains and waste products in the vitreous. One of these cellular remains is phosphatidylethanolamine, which may contribute to the formation of asteroid bodies in the vitreous. ${ }^{16}$ It should be noted that this interesting theory remains so-far not proven in an experimental setting.

\section{Clinical Diagnosis and Differential Diagnoses}

Asteroid hyalosis is rarely symptomatic, which may be due to the low density of the asteroid bodies and their position in the vitreous. ${ }^{17,18}$ Hence, there is often another reason for the consultation, and asteroid hyalosis is often an incidental finding. This is an important aspect of the 


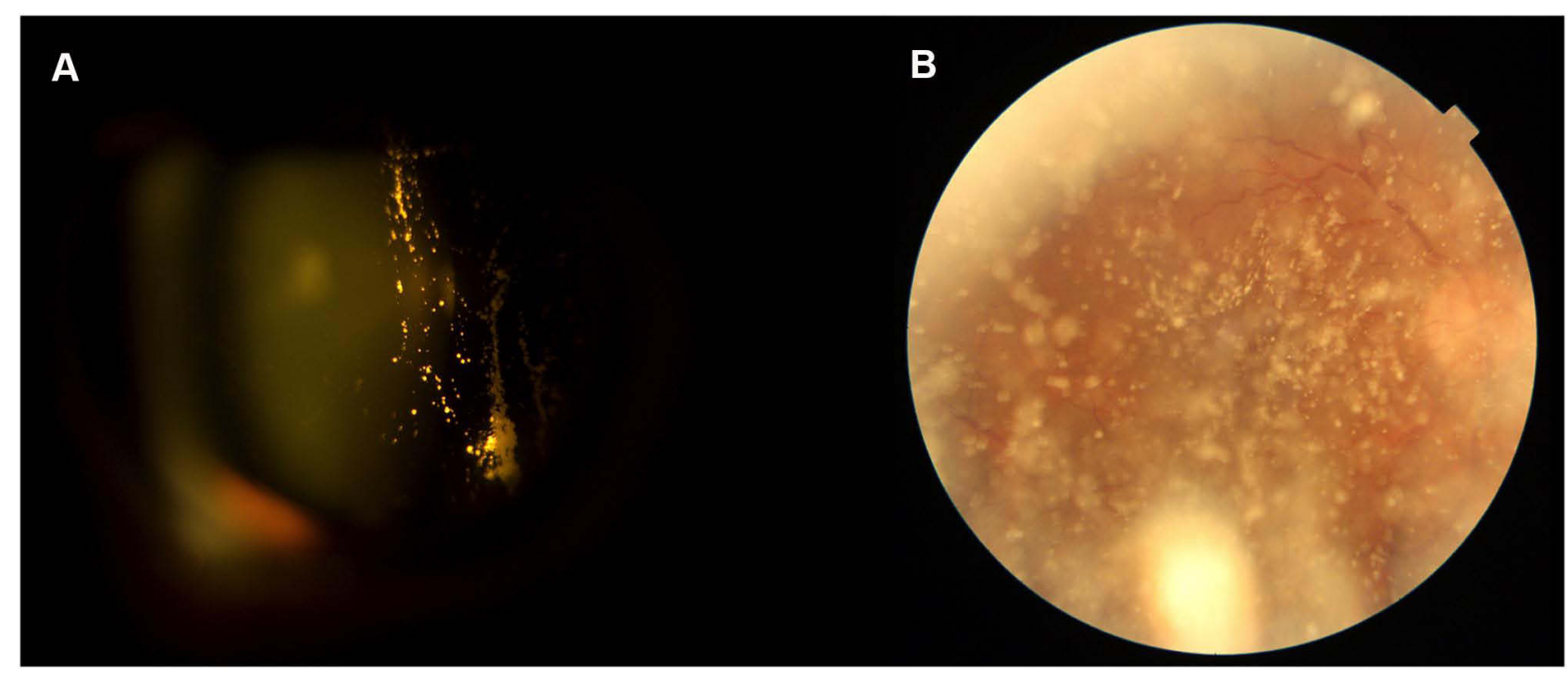

Figure I Appearance of asteroid hyalosis in slit-lamp with direct focal illumination (A) and retinal examination here seen using a fundus photography (B).

disease, as asteroid hyalosis rarely is the ophthalmic reason for the patient's complaints and other conditions should be ruled out.

Vitreous opacities can be visualized in eyes with pupillary dilation. The biomicroscopy slit-lamp examination with direct focal illumination will reveal vitreous opacities in the anterior part of the vitreous (Figure 1). Fundus examination with 90D lens or indirect ophthalmoscopy can reveal vitreous opacities and they may challenge and obstruct the further examination of the retina (Figure 1). Asteroid hyalosis is seen as numerous vitreous opacities that are round in shape, bright yellow in appearance, and moves with the vitreous with eye movements but avoids gravitating downwards. Optical coherence tomography show hyperreflective foci in the vitreous (Figure 2). Finally, B-scan ultrasonography shows small, round, nongravitating hyperechoic elements in the vitreous, that can be confluent in severe cases (Figure 2).

There are other causes for vitreous opacities than asteroid hyalosis and thorough examination is crucial for correct diagnosis and ruling out differential diagnoses (Table 1). This is important since these differential diagnoses may require timely treatment. Vitreous degeneration is a more common cause of vitreous opacities. In the case of vitreous degeneration and vitreous detachment, retinal tears are important to diagnose early for treatment and prevention of rhegmatogenous retinal detachment. Vitreous hemorrhage is a condition secondary to trauma or other diseases, which should lead to thorough examination of the retina for the cause and location of bleeding.
Examples of more rare causes of vitreous opacities are synchysis scintillans and amyloidosis. Synchysis scintillans is a rare condition which can be seen in a blind eye as a consequence of chronic vitreous hemorrhage, where the degradation of blood leads to formation of yellow-brown cholesterol crystals that gravitate downwards unlike asteroid hyalosis. In amyloidosis, there is fibrillary protein formation in the vitreous which takes on the white-bright, glass wool appearance in the anterior vitreous right behind the lens. Finally, inflammation, infection, or malignancy leads to a vitritis and vitreous opacities, which are also important differential diagnoses.

\section{Clinical Challenges}

Presence of asteroid hyalosis can lead to clinical challenges in preparation and outcomes of cataract surgery as well as retinal examination.

\section{Cataract Surgery}

When preparing for cataract surgery, one must be able to accurately measure refraction and axial length. Asteroid bodies can lead to refractive measures from autorefraction based on a reference point within the vitreous rather than the retina, leading to a relatively more hyperopic result. ${ }^{19}$ When measuring axial length using A-scan ultrasound, asteroid bodies can lead to early ultrasound echoes, which leads to falsely short axial length. ${ }^{20-22}$ In a study of 20 patients with unilateral asteroid hyalosis, Allison et al. found that five eyes $(25 \%)$ had falsely short axial length measurements of more than $1 \mathrm{~mm}$ using automated 

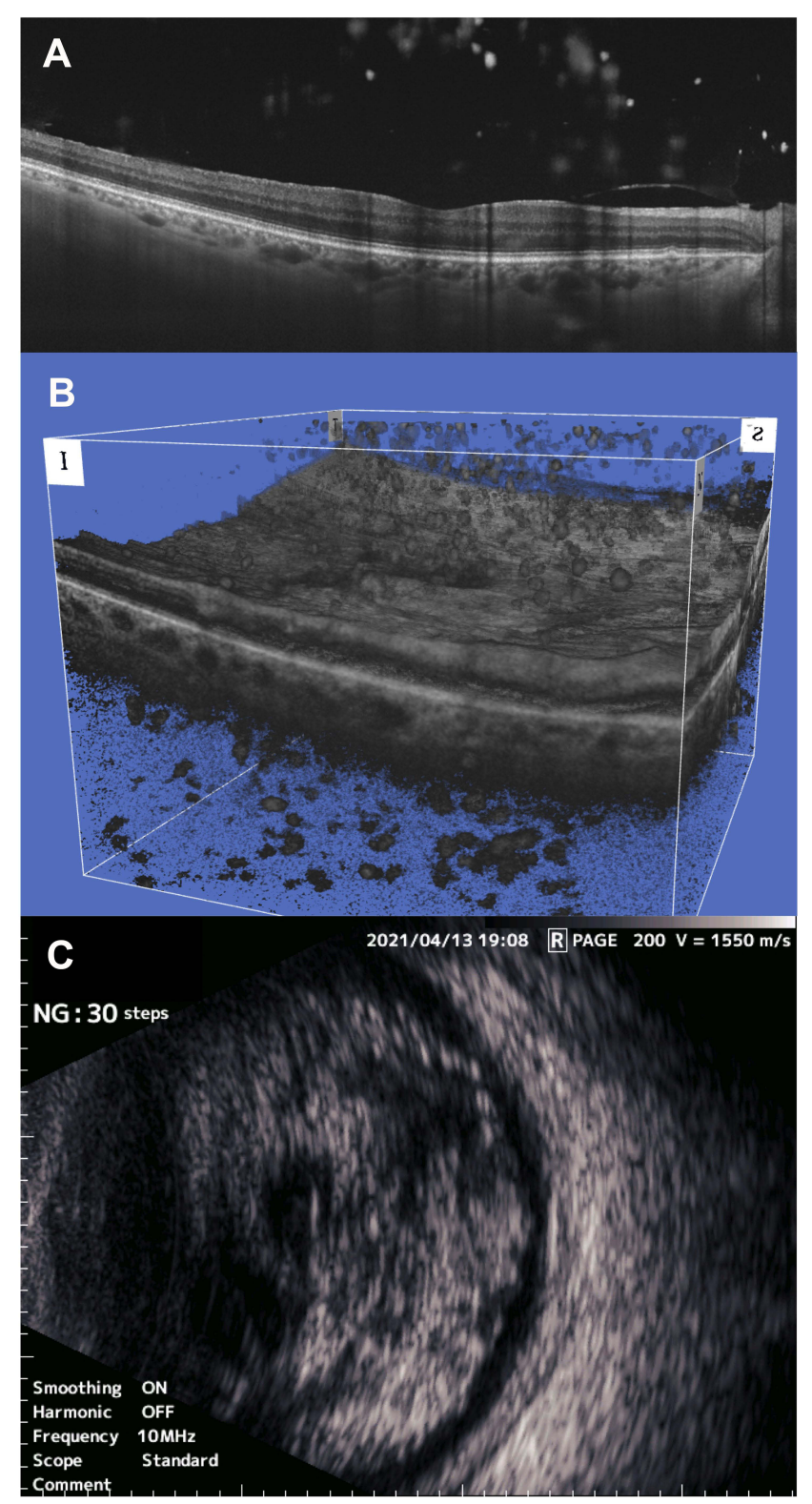

Figure 2 Asteroid hyalosis is seen as numerous hyperreflective foci in the vitreous in cross-sectional optical coherence tomography (OCT) scans (A) as well as 3D OCT (B), and as small round hyperechoic elements in the vitreous in B-scan ultrasonography (C)

biometry, which would result in $>2.5$ diopters of error in the implanted IOL power. ${ }^{20}$ Considering that modern methods of axial length measurements do not use ultrasound, the impact of this source of measurement bias may be limited to select cases, e.g. a dense cataract which necessitates the use of ultrasound for the measurements. It remains unknown to which extent modern optical coherence-based methods of axial length measurements are affected by asteroid hyalosis. However, from a practical perspective, we recommend measuring refraction and axial length using multiple methods, critically approach available measures, as well as consider the measures of the fellow eye. Silicone-based IOLs in eyes with asteroid hyalosis are reported to undergo surface calcification, ${ }^{23,24}$ which is not seen after using acrylic-based IOLs. ${ }^{24}$ These surface calcifications lead to opacification not easily removable by laser capsulotomy, and many such cases eventually undergo IOL exchange. ${ }^{25,26}$ Finally, it should be noted that asteroid hyalosis can also present challenges during surgery. Reflections from the individual asteroid bodies can lead to difficulties in viewing the posterior capsule. $^{27}$

\section{Retinal Examination}

Retinal examination can be severely challenged by asteroid hyalosis as the vitreous opacities can make it extremely difficult to obtain a sufficiently detailed overview of the retina. Fundus photographs often lead to a blurry retina. One study of photographic diabetic retinopathy screening found that asteroid hyalosis was seen in $0.4 \%$ of the screened population, but the primary cause of ungradable fundus photographs in $8.5 \%$ of the population.${ }^{28}$ For fundus examination, better results on-site can be obtained through direct ophthalmoscopy. For fundus photographs or retinal angiography, better results may be obtained using scanning laser ophthalmoscopy-based systems, such as OPTOS (Figure 3). ${ }^{29-31}$ Optical coherence tomography (OCT) often yields successful visualization of the retinal layers and the artifact from the asteroid bodies does not induce significant impact on the readability of the scans, ${ }^{32,33}$ and it has been reported that swept-source based systems may be superior to spectral-domain based systems. ${ }^{34}$ Further, it has been reported that optical coherence tomography angiography including widefield systems can successfully penetrate through the asteroid bodies and visualize neovascularizations, microaneurysms, and capillary dropout zones. ${ }^{35,36}$ Finally, B-scan ultrasonography can always penetrate beyond the asteroid bodies and provide an overview of the retina although the structural detail is insufficient for monitoring a range of retinal diseases. $^{30,37}$

\section{Treatment}

Treatment of vitreous opacities including asteroid hyalosis is usually done by performing vitrectomy. However, since asteroid hyalosis rarely causes symptoms, asteroid hyalosis by itself is rarely the actual indication of treatment. ${ }^{38} \mathrm{In}$ a study of patients who underwent vitrectomy with peeling for epiretinal membrane, Mouna et al. showed that patients 
Table I Differential Diagnoses of Asteroid Hyalosis

\begin{tabular}{|c|c|c|c|c|}
\hline $\begin{array}{l}\text { Differential } \\
\text { Diagnosis }\end{array}$ & Symptoms & Clinical Features and Diagnosis & Clinical Work-Up & $\begin{array}{l}\text { Treatment } \\
\text { Needed? }\end{array}$ \\
\hline \multicolumn{5}{|c|}{ Common conditions } \\
\hline $\begin{array}{l}\text { Posterior } \\
\text { vitreous } \\
\text { detachment. }\end{array}$ & $\begin{array}{l}\text { Floaters (spider webs, strings, } \\
\text { transparent ring). }\end{array}$ & $\begin{array}{l}\text { Fundus examination will reveal the posterior } \\
\text { vitreous detachment. A Weiss ring may be } \\
\text { visible. The hyperreflective delineation of the } \\
\text { vitreous may no longer be visible on optical } \\
\text { coherence tomography. B-scan } \\
\text { ultrasonography may reveal a thin hyperechoic } \\
\text { line corresponding to the posterior vitreous. }\end{array}$ & $\begin{array}{l}\text { The majority of these cases are mild without } \\
\text { any complications. However, retinal breaks or } \\
\text { tears are important to identify for } \\
\text { prophylactic laser therapy to prevent retinal } \\
\text { detachment. Some cases may even present } \\
\text { with rhegmatogenous retinal detachment. }\end{array}$ & $\begin{array}{l}\text { Yes, cases } \\
\text { with retinal } \\
\text { complications. }\end{array}$ \\
\hline $\begin{array}{l}\text { Vitreous } \\
\text { hemorrhage }\end{array}$ & $\begin{array}{l}\text { Sudden onset of floaters and } \\
\text { blurred vision. A more severe } \\
\text { bleeding will give rise to a } \\
\text { severe vision loss. }\end{array}$ & $\begin{array}{l}\text { Examination of anterior vitreous reveals cells } \\
\text { that are predominantly in a red hue. Fundus } \\
\text { examination may not be possible due to the } \\
\text { extent of the hemorrhage. B-scan } \\
\text { ultrasonography will show heterogenous } \\
\text { echogenic material in the vitreous. }\end{array}$ & $\begin{array}{l}\text { Determine underlying pathology to the extent } \\
\text { it is possible to treat what needs and can be } \\
\text { treated. Diagnoses to consider include } \\
\text { proliferative diabetic retinopathy, posterior } \\
\text { vitreous detachment with complications, } \\
\text { venous occlusion, any vascular or } \\
\text { inflammatory with ischemia and retinal } \\
\text { neovascularization, retinal breaks, retinal } \\
\text { tears, retinal detachment, and tumor. }\end{array}$ & Yes \\
\hline Vitritis & $\begin{array}{l}\text { Blurred vision, floaters, pain, } \\
\text { photophobia, and hyperemia. }\end{array}$ & $\begin{array}{l}\text { Examination of anterior vitreous reveals cells } \\
\text { that are in a white hue. Some cases are also } \\
\text { accompanied by cells and flare in the anterior } \\
\text { chamber. Vitreous condensation, vitreous } \\
\text { haze, snowballs, and snowbanking may be } \\
\text { seen. }\end{array}$ & Work-up protocol for uveitis. & Yes \\
\hline \multicolumn{5}{|l|}{ Rare conditions } \\
\hline $\begin{array}{l}\text { Synchysis } \\
\text { scintillans }\end{array}$ & $\begin{array}{l}\text { Asymptomatic condition in a } \\
\text { blind eye with long history of } \\
\text { chronic hemorrhage or uveitis. }\end{array}$ & $\begin{array}{l}\text { Examination of the vitreous reveals golden/ } \\
\text { brown colored crystals which sink inferiorly } \\
\text { when the eye is immobile. }\end{array}$ & $\begin{array}{l}\text { Underlying pathology is usually known when } \\
\text { synchysis scintillans is present, as the eye is } \\
\text { usually blind due to a long history of chronic } \\
\text { hemorrhage or uveitis. }\end{array}$ & No \\
\hline Amyloidosis & $\begin{array}{l}\text { Blurred vision, floaters, and } \\
\text { photophobia. }\end{array}$ & $\begin{array}{l}\text { Examination of the vitreous will reveal } \\
\text { opacities with a granular appearance in the } \\
\text { early stages. Later, the opacities will aggregate } \\
\text { to a glass wool-like appearance. Exudates, } \\
\text { peripheral retinal neovascularization, and } \\
\text { cotton wool spots can be observed upon } \\
\text { retinal examination. }\end{array}$ & $\begin{array}{l}\text { Vitreous sampling allows a pathological } \\
\text { examination that reveals a fibrillar } \\
\text { morphology and the amyloid proteins will } \\
\text { reveal their specific histological characteristics } \\
\text { when Congo red stain is applied. Search for } \\
\text { the extent of amyloid infiltration: orbit, } \\
\text { eyelids, conjunctiva, cornea, iris, and also } \\
\text { consider a work-up plan for potential } \\
\text { extraocular manifestations. Further } \\
\text { multidisciplinary work-up is often needed. }\end{array}$ & Yes \\
\hline Endophthalmitis & $\begin{array}{l}\text { Blurred vision, pain, } \\
\text { hyperemia. Fever can be } \\
\text { present if endogenous } \\
\text { endophthalmitis. }\end{array}$ & $\begin{array}{l}\text { Anterior chamber inflammation and } \\
\text { hypopyon. Examination of anterior vitreous } \\
\text { reveals cells that are in a white hue. Many } \\
\text { cases are also accompanied by eyelid edema } \\
\text { and conjunctival congestion. }\end{array}$ & $\begin{array}{l}\text { Aqueous and vitreous sampling and } \\
\text { microbiology are important aspects of the } \\
\text { work-up. }\end{array}$ & Yes \\
\hline $\begin{array}{l}\text { Malignancy e.g. } \\
\text { lymphoma }\end{array}$ & Floaters, blurred vision. & $\begin{array}{l}\text { Examination of anterior vitreous reveals cells } \\
\text { that are in a white hue often with a dense } \\
\text { posterior vitreous membrane. This condition } \\
\text { can be difficult to differentiate from vitritis. } \\
\text { Large, multifocal, yellow-colored chorioretinal } \\
\text { lesions may be present upon fundus } \\
\text { examination. }\end{array}$ & $\begin{array}{l}\text { Diagnostic vitrectomy with flow cytometry } \\
\text { and pathological examination of a vitreous } \\
\text { sample is necessary for the diagnosis. Further } \\
\text { multidisciplinary work-up is often needed. }\end{array}$ & Yes \\
\hline
\end{tabular}




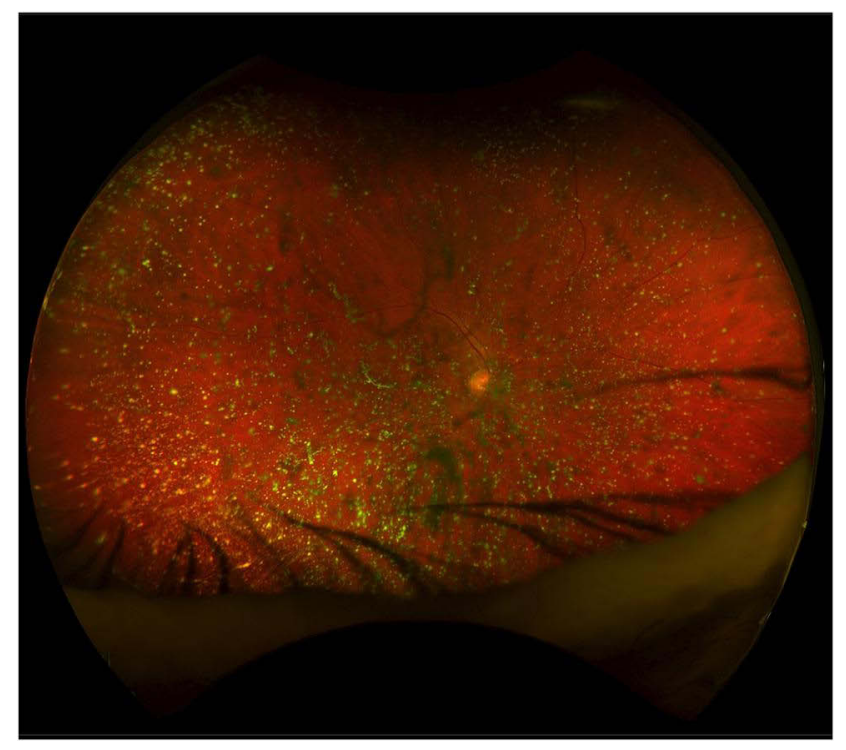

Figure 3 Scanning laser ophthalmoscopy-based systems such as OPTOS may enable retinal examination to a certain degree.

with epiretinal membrane with or without asteroid hyalosis had similar anatomical and functional outcomes, including the best-corrected visual acuity. ${ }^{38}$ Thus, prognosis is often good without treatment, but the rare cases with increasingly dense asteroid hyalosis may eventually impact vision and in these cases a vitrectomy may be of benefit to the patient. Of note, vitrectomy in $\mathrm{AH}$ is often challenging due to vitreoschisis and abnormal vitreoretinal adhesion increasing the risk of complications. ${ }^{39}$

Indications for treatment include floaters, glare, and blurred vision. However, considering that the disease is often asymptomatic, it can be challenging to recommend vitrectomy as a means to relieve the patient from the symptoms. One approach to objectively evaluate need for treatment may be to correlate higher-order aberrations with the patient complaints. Yokoyama et al. reported on three patients with dense asteroid hyalosis. All complained of glare and floaters and their eyes with asteroid hyalosis were measured to high level of internal higher-order aberrations. ${ }^{40}$ Vitrectomy decreased the internal higherorder aberrations and relieved the patients of their visual symptoms. ${ }^{40}$ In a study of two cases, Sato et al. reported on the use of the internal higher-order aberrations for treatment decision. ${ }^{41}$ In one case, the clinical examination revealed mild cataract and asteroid hyalosis in one eye, and only cataract in the other eye. ${ }^{41}$ The internal higherorder aberration was within the normal range in both eyes. ${ }^{41}$ After cataract surgery, the vision improved and no treatment for the asteroid hyalosis was needed. ${ }^{41}$ In the other case, the clinical examination revealed mild cataract and asteroid hyalosis in both eyes, but here the internal higher-order aberration was higher in both eyes, which led to the decision of performing phacovitrectomy in both eyes which improved vision and visual complaints. ${ }^{41}$ Based on these case reports, it can be suggested to measure higher-order aberrations to evaluate potential contribution of relevant visual symptoms for decision making towards vitrectomy, and to consider the relevance of phacovitrectomy when the patient presents with combined cataract and asteroid hyalosis.

Vitrectomy due to asteroid hyalosis may also be needed, where other retinal pathology requires diagnosis, observation, or treatment. ${ }^{2}$ Since asteroid hyalosis is a condition with an increasing prevalence with age, it is also a condition which challenges the diagnosis and the progression of diseases that increase in prevalence with age, ${ }^{11,42-44}$ e.g. age-related macular degeneration, diabetic retinopathy, retinal vascular occlusions, and retinal tears. Focal laser treatment or panretinal photocoagulation treatment may also be difficult to perform due to the asteroid bodies. $^{45}$

\section{Conclusion}

Asteroid hyalosis is a benign cause of vitreous opacities. It is a relatively rare condition, and more prevalent in males and in increasing age. Asteroid hyalosis is rarely the cause of visual symptoms, and other causes of vision loss should be extensively investigated before considering asteroid hyalosis as the primary cause of the patient's symptoms. Differential diagnoses should be ruled out, as they may require a completely different clinical approach and therapy. Presence of asteroid hyalosis leads to clinical challenges in cataract surgery and in fundus examination. Treatment with vitrectomy may be indicated in select cases, especially if diagnosis, observation, and treatment of underlying retinal pathologies are necessary. Current evidence to guide clinical practice is largely based on anecdotal evidence and clinical experience, which calls for more studies on asteroid hyalosis from a clinical perspective, e.g. large randomized clinical trials where symptomatic eyes are randomized to vitrectomy versus observation.

\section{Disclosure}

The authors report no conflicts of interest in this work. 


\section{References}

1. Benson A. Diseases of the vitreous: a case of 'monocular asteroid hyalitis'. Trans Ophthalmol Soc UK. 1894;14:101.

2. Khoshnevis M, Rosen S, Sebag J. Asteroid hyalosis-a comprehensive review. Surv Ophthalmol. 2019;64(4):452-462. doi:10.1016/j. survophthal.2019.01.008

3. Komatsu H, Kamura Y, Ishi K, et al. Fine structure and morphogenesis of asteroid hyalosis. Med Electron Microsc. 2003;36(2):112-119. doi:10.1007/s00795-002-0211-y

4. Miller H, Miller B, Rabinowitz H, et al. Asteroid bodies-an ultrastructural study. Invest Ophthalmol Vis Sci. 1983;24(1):133-136.

5. Streeten BW. Vitreous asteroid bodies. Ultrastructural characteristics and composition. Arch Ophthalmol. 1982;100(6):969-975. doi:10.1001/archopht.1982.01030030977016

6. Topilow HW, Kenyon KR, Takahashi M, et al. Asteroid hyalosis. Biomicroscopy, ultrastructure, and composition. Arch Ophthalmol. 1982;100(6):964-968. doi:10.1001/archopht.1982.01030030972015

7. Winkler J, Lünsdorf $\mathrm{H}$. Ultrastructure and composition of asteroid bodies. Invest Ophthalmol Vis Sci. 2001;42(5):902-907.

8. Moss SE, Klein R, Klein BE, et al. Asteroid hyalosis in a population: the Beaver Dam eye study. Am J Ophthalmol. 2001;132(1):70-75. doi:10.1016/S0002-9394(01)00936-9

9. Mitchell P, Wang MY, Wang JJ. Asteroid hyalosis in an older population: the Blue Mountains Eye Study. Ophthalmic Epidemiol. 2003;10 (5):331-335. doi:10.1076/opep.10.5.331.17324

10. Elbaz H, Schuster AK, Nickels S, et al. Epidemiologic analysis of asteroid hyalosis and associations: the Gutenberg Health Study. Ophthalmology. 2021;128(2):328-330. doi:10.1016/j.ophtha.2020.07.008

11. Møller-Lorentzen TB, Eckmann-Hansen C, Faber C, et al. Global prevalence of asteroid hyalosis and projection of its future burden: a systematic review and meta-analysis. Acta Ophthalmol. 2020;98 (8):755-762. doi:10.1111/aos.14465

12. Bergren RL, Brown GC, Duker JS. Prevalence and association of asteroid hyalosis with systemic diseases. Am J Ophthalmol. 1991;111 (3):289-293. doi:10.1016/S0002-9394(14)72311-6

13. Fawzi AA, Vo B, Kriwanek R, et al. Asteroid hyalosis in an autopsy population: the University of California at Los Angeles (UCLA) experience. Arch Ophthalmol. 2005;123(4):486-490. doi:10.1001/ archopht.123.4.486

14. Hatfield RE, Gastineau CF, Rucker CW. Asteroid bodies in the vitreous: relationship to diabetes and hypercholesterolemia. Proc Staff Meet Mayo Clin. 1962;37:513-514.

15. Kim JH, Roh MI, Byeon SH, et al. Prevalence of and risk factors for asteroid hyalosis in Seoul, Korea. Retina. 2008;28(10):1515-1521 doi:10.1097/IAE.0b013e318185ea3c

16. Ikeda Y, Hisatomi T, Murakami Y, et al. Retinitis pigmentosa associated with asteroid hyalosis. Retina. 2010;30(8):1278-1281. doi:10.1097/IAE.0b013e3181dcfc0a

17. Ochi R, Sato B, Morishita S, et al. Case of asteroid hyalosis that developed severely reduced vision after cataract surgery. $B M C$ Ophthalmol. 2017;17(1):68. doi:10.1186/s12886-017-0467-6

18. Noda S, Hayasaka S, Setogawa T. Patients with asteroid hyalosis and visible floaters. Jpn J Ophthalmol. 1993;37(4):452.

19. Wong SCK, Sampath R. Erroneous automated refraction in a case of asteroid hyalosis. J Cataract Refract Surg. 2002;28(9):1707-1708. doi:10.1016/S0886-3350(01)01224-X

20. Allison KL, Price J, Odin L, et al. Asteroid hyalosis and axial length measurement using automated biometry. $J$ Cataract Refract Surg. 1991;17(2):181-186. doi:10.1016/S0886-3350(13)80248-9

21. Martin RG, Safir A. Asteroid hyalosis affecting the choice of intraocular lens implant. J Cataract Refract Surg. 1987;13(1):62-65. doi:10.1016/S0886-3350(87)80014-7

22. Hartstein I, Barke RM. Axial length measurement discrepancies in asteroid hyalosis. Br J Ophthalmol. 1991;75(3):191. doi:10.1136/ bjo.75.3.191
23. Wackernagel W, Ettinger $\mathrm{K}$, Weitgasser $\mathrm{U}$, et al. Opacification of a silicone intraocular lens caused by calcium deposits on the optic. $J$ Cataract Refract Surg. 2004;30(2):517-520. doi:10.1016/S08863350(03)00672-2

24. Stringham J, Werner L, Monson B, et al. Calcification of different designs of silicone intraocular lenses in eyes with asteroid hyalosis. Ophthalmology. 2010;117(8):1486-1492. doi:10.1016/j. ophtha.2009.12.032

25. Espandar L, Mukherjee N, Werner L, et al. Diagnosis and management of opacified silicone intraocular lenses in patients with asteroid hyalosis. J Cataract Refract Surg. 2015;41(1):222-225. doi:10.1016/ j.jcrs.2014.11.009

26. Platt SM, Iezzi R, Mahr MA, et al. Surgical removal of dystrophic calcification on a silicone intraocular lens in association with asteroid hyalosis. J Cataract Refract Surg. 2017;43(12):1608-1610. doi:10.1016/j.jcrs.2017.09.026

27. Mishra C, Tripathy K. Asteroid Hyalosis. In: StatPearls [Internet]. Asteroid Hyalosis. Treasure Island (FL): StatPearls Publishing; 2021 Feb 14.

28. Wright AD, Yang YC, Dodson PM. Asteroid hyalosis and photographic diabetic retinopathy screening. Diabet Med. 2010;27 (9):1093. doi:10.1111/j.1464-5491.2010.03038.x

29. Win PH, Young TA. Optos Panoramic200A fluorescein angiography for proliferative diabetic retinopathy with asteroid hyalosis. Semin Ophthalmol. 2007;22(2):67-69. doi:10.1080/0882053 0701331644

30. Motiani MV, McCannel CA, Almanzor R, et al. Diagnosis of choroidal melanoma in dense asteroid hyalosis. Semin Ophthalmol. 2017;32(2):257-259.

31. Saurabh K, Roy R, Chowdhury M. Efficacy of multicolor imaging in patients with asteroid hyalosis: seeing the unseen. JAMA Ophthalmol. 2018;136(4):446-447. doi:10.1001/jamaophthalmo 1.2018 .0026

32. Hwang JC, Barile GR, Schiff WM, et al. Optical coherence tomography in asteroid hyalosis. Retina. 2006;26(6):661-665. doi:10.1097/01.iae.0000224502.33905.66

33. Browning DJ, Fraser CM. Optical coherence tomography to detect macular edema in the presence of asteroid hyalosis. $A m ~ J$ Ophthalmol. 2004;137(5):959-961. doi:10.1016/j.ajo.2003.11.049

34. Alasil T, Adhi M, Liu JJ, et al. Spectral-domain and swept-source OCT imaging of asteroid hyalosis: a case report. Ophthalmic Surg Lasers Imaging Retina. 2014;45(5):459-461. doi:10.3928/2325816020140909-01

35. Rani PK, Prajapati RC. Role of OCT angiography in the detection of retinal vascular and macular abnormalities in subjects with asteroid hyalosis. Semin Ophthalmol. 2018;26:1-5.

36. Belenje A, Rani PK. Role of wide-angle optical coherence tomography angiography in detection of proliferative diabetic retinopathy in a patient with dense asteroid hyalosis. BMJ Case Rep. 2020;13(9): e237248. doi:10.1136/bcr-2020-237248

37. De La Hoz Polo M, Torramilans Lluís A, Pozuelo Segura O, et al. Ocular ultrasonography focused on the posterior eye segment: what radiologists should know. Insights Imaging. 2016;7(3):351-364. doi:10.1007/s13244-016-0471-z

38. Mouna A, Berrod JP, Conart JB. Visual outcomes of pars plana vitrectomy with epiretinal membrane peeling in patients with asteroid hyalosis: a Matched Cohort Study. Ophthalmic Res. 2017;58(1):3539. doi:10.1159/000468990

39. Mochizuki Y, Hata Y, Kita T, et al. Anatomical findings of vitreoretinal interface in eyes with asteroid hyalosis. Graefes Arch Clin Exp Ophthalmol. 2009;247(9):1173-1177. doi:10.1007/s00417-0091095-5

40. Yokoyama S, Kojima T, Kaga T, et al. Increased internal higher-order aberrations as a useful parameter for indication of vitrectomy in three asteroid hyalosis cases. BMJ Case Rep. 2015;2015:bcr2015211704. doi:10.1136/bcr-2015-211704 
41. Sato T, Koh S, Mori R, et al. Impact of asteroid hyalosis on internal higher-order aberrations in eyes with cataract accompanied by acoustic shadows on swept-source optical coherence tomography examination. J Cataract Refract Surg. 2020;46(12):e1-e4. doi:10.1097/j. jcrs.0000000000000303

42. Li JQ, Terheyden JH, Welchowski T, et al. Prevalence of retinal vein occlusion in europe: a systematic Review and Meta-Analysis. Ophthalmologica. 2019;241(4):183-189. doi:10.1159/000494224

43. Sedeh FB, Scott DAR, Subhi Y, et al. Prevalence of neovascular agerelated macular degeneration and geographic atrophy in Denmark. Dan Med J. 2017;64(11):A5422.
44. Li JQ, Welchowski T, Schmid M, et al. Prevalence, incidence and future projection of diabetic eye disease in Europe: a systematic review and meta-analysis. Eur J Epidemiol. 2020;35(1):11-23. doi:10.1007/s10654-019-00560-z

45. Lambrou FH Jr, Sternberg P Jr, Meredith TA, et al. Vitrectomy when asteroid hyalosis prevents laser photocoagulation. Ophthalmic Surg. 1989;20(2):100-102.

\section{Publish your work in this journal}

Clinical Ophthalmology is an international, peer-reviewed journal covering all subspecialties within ophthalmology. Key topics include: Optometry; Visual science; Pharmacology and drug therapy in eye diseases; Basic Sciences; Primary and Secondary eye care; Patient Safety and Quality of Care Improvements. This journal is indexed on PubMed

Submit your manuscript here: https://www.dovepress.com/clinical-ophthalmology-journal
Central and CAS, and is the official journal of The Society of Clinical Ophthalmology (SCO). The manuscript management system is completely online and includes a very quick and fair peer-review system, which is all easy to use. Visit http://www.dovepress.com/ testimonials.php to read real quotes from published authors. 